\title{
SEX RATIO* OF STILLBIRTHS RELATED TO BIRTH WEIGHT
}

\author{
BY \\ THOMAS MCKEOWN and C. R. LOWE \\ From the Department of Social Medicine, University of Birmingham
}

It is well known that more males than females are stillborn: of stillbirths notified in England and Wales (1939-47), 53.8 per cent. were males. This is because:

(1) There are more male foetuses at risk, for, as indicated by the sex ratio of stillbirths and live births combined (51.5 for England and Wales, 1939-47), there are more males than females in the uterus at 28 weeks, the time from which stillbirths are notified. The male excess at 28 weeks must result from one or both of two causes:

(a) a high sex ratio at conception

(b) a greater loss of females than of males as abortions in the period between conception and notification.

On the first point there is no direct evidence, and on the second it is generally believed that the sex ratio of abortions is above 50. But reasons have been suggested in support of the view that the gross inadequacy of data from the early months of gestation must leave the sex ratio of abortions, and hence the sex ratio at conception, an open question (McKeown and Lowe, 1951).

(2) Stillbirth rates are higher for male than for female births; this follows from the fact that the sex ratio of stillbirths is higher than that of total births. In England and Wales (1939-47), the sex-specific stillbirth rates (per thousand related total births) were 31.8 and 29.0 for males and females respectively. Various explanations have been suggested for this difference, but none is supported by any substantial evidence.

The purpose of this communication is to explore the association between the sex ratio of stillbirths and birth weight. It is known that weight distributions are different for male and female births, and the incidence of certain causes of death (for example difficult labour) is associated with birth weight and is different for the two sexes. Hence it is of interest to enquire whether the difference in the sexspecific stillbirth rates is reduced when births of corresponding weight are compared. If it is found to be reduced, this would in part account for the fact that the sex ratio of stillbirths is higher than that of the total births from which they are drawn.

* Sex ratio is expressed as the percentage of males $\frac{M}{M+F} \times 100$. 


\section{MATERIAL AND RESUltS}

For the years 1945-49 we obtained from city records data for all stillbirths notified in Birmingham. During this period the Maternity and Child Welfare Department, assisted by the attendant at the birth (doctor or midwife), completed a card in respect of each stillbirth. The information recorded included sex, birth weight (lb. and oz.), and the certified cause of stillbirth. In the 5 years there were 2,388 stillbirths, for seventeen of which birth weight was unspecified. The requisite data are thus available for 2,371 stillbirths.

We also make use of valuable data recently published by Baumgartner and others (1950), which give the sex and birth weight (g.), but not the cause of death, for foetal deaths subsequent to 20 weeks of gestation notified in New York City during the two years 1939-40. There were 6,978 foetal deaths, for 1,871 (27 per cent.) of which weight was unspecified. The authors have assigned weights to these 1,871 births according to the duration of gestation, using information about the correlation between gestation and weight obtained from the stillbirths for which both variables were recorded.

Weight distributions of the related populations of live births are available for the New York data, and for Birmingham data for one year only (1947).

TABLE I

Sex Ratio of Births subsequent to 28 Weeks of Gestation Related to Birth Weight (BIRMINGHAM)

\begin{tabular}{|c|c|c|c|c|c|c|}
\hline \multirow{3}{*}{$\begin{array}{c}\text { Birth Weight } \\
\text { (lb.) }\end{array}$} & \multicolumn{3}{|c|}{ Stillbirths (1945-1948) } & \multicolumn{3}{|c|}{ Total Births (1947) } \\
\hline & \multicolumn{2}{|c|}{ Percentage Distribution } & \multirow{2}{*}{ Sex Ratio } & \multicolumn{2}{|c|}{ Percentage Distribution } & \multirow{2}{*}{ Sex Ratio } \\
\hline & Males & Females & & Males & Females & \\
\hline Under 3 & $\begin{array}{l}10 \cdot 1 \\
(127)\end{array}$ & $\begin{array}{l}15 \cdot 8 \\
(176)\end{array}$ & $41 \cdot 9$ & $\begin{array}{l}0.8 \\
(92)\end{array}$ & $\begin{array}{l}0 \cdot 7 \\
(72)\end{array}$ & $56 \cdot 1$ \\
\hline $3-$ & $\begin{array}{r}9 \cdot 7 \\
(122)\end{array}$ & $\begin{array}{l}11 \cdot 3 \\
(126)\end{array}$ & $49 \cdot 2$ & $\begin{array}{l}0 \cdot 7 \\
(87)\end{array}$ & $\begin{array}{l}0 \cdot 8 \\
(82)\end{array}$ & $51 \cdot 5$ \\
\hline 4 & $\begin{array}{l}11 \cdot 8 \\
(149)\end{array}$ & $\begin{array}{l}12 \cdot 8 \\
(143)\end{array}$ & $51 \cdot 0$ & $\begin{array}{r}1 \cdot 7 \\
(195)\end{array}$ & $\begin{array}{r}2 \cdot 0 \\
(225)\end{array}$ & $46 \cdot 4$ \\
\hline $5-$ & $\begin{array}{l}11 \cdot 5 \\
(145)\end{array}$ & $\begin{array}{l}12 \cdot 8 \\
(142)\end{array}$ & $50 \cdot 5$ & $\begin{array}{r}6 \cdot 0 \\
(701)\end{array}$ & $\begin{array}{r}8 \cdot 1 \\
(895)\end{array}$ & $43 \cdot 9$ \\
\hline 6- & $\begin{array}{l}16 \cdot 4 \\
(206)\end{array}$ & $\begin{array}{l}16 \cdot 8 \\
(187)\end{array}$ & $52 \cdot 4$ & $\begin{array}{c}20 \cdot 4 \\
(2,402)\end{array}$ & $\begin{array}{c}25 \cdot 7 \\
(2,825)\end{array}$ & $46 \cdot 0$ \\
\hline 7- & $\begin{array}{l}19 \cdot 0 \\
(239)\end{array}$ & $\begin{array}{l}18 \cdot 1 \\
(201)\end{array}$ & $54 \cdot 3$ & $\begin{array}{c}34 \cdot 8 \\
(4,096)\end{array}$ & $\begin{array}{c}36 \cdot 1 \\
(3,969)\end{array}$ & $50 \cdot 8$ \\
\hline 8- & $\begin{array}{l}12 \cdot 8 \\
(161)\end{array}$ & $\begin{array}{l}8 \cdot 5 \\
(95)\end{array}$ & $62 \cdot 9$ & $\begin{array}{c}24 \cdot 5 \\
(2,880)\end{array}$ & $\begin{array}{c}20 \cdot 0 \\
(2,202)\end{array}$ & $56 \cdot 7$ \\
\hline 9- & $\begin{array}{l}5 \cdot 4 \\
(68)\end{array}$ & $\begin{array}{r}2 \cdot 7 \\
(30)\end{array}$ & $69 \cdot 4$ & $\begin{array}{c}8 \cdot 5 \\
(1,005)\end{array}$ & $\begin{array}{r}5 \cdot 2 \\
(572)\end{array}$ & $63 \cdot 7$ \\
\hline 10 and over & $\begin{array}{c}3 \cdot 3 \\
(41)\end{array}$ & $\begin{array}{l}1 \cdot 2 \\
(13)\end{array}$ & $75 \cdot 9$ & $\begin{array}{r}2 \cdot 7 \\
(317)\end{array}$ & $\begin{array}{r}1 \cdot 3 \\
(147)\end{array}$ & $68 \cdot 3$ \\
\hline Total & $\begin{array}{c}100 \\
(1,258)\end{array}$ & $\begin{array}{c}100 \\
(1,113)\end{array}$ & $53 \cdot 1$ & $\begin{array}{c}100 \\
(11,775)\end{array}$ & $\begin{array}{c}100 \\
(10,989)\end{array}$ & $51 \cdot 7$ \\
\hline
\end{tabular}


The data can be examined in various ways, of which perhaps the most satisfactory is to begin by noting that:

(a) the sex ratios of stillbirths (all weights) are 53.1 and 55.0 for Birmingham and New York respectively

(b) the sex ratios vary with birth weight (Tables I and II).

In Birmingham the ratios increase fairly regularly with increasing weight; in New York the same is true, with the difference that the sex ratio is distinctly raised for births at the lowest weight recorded (" under 1,000 g.": sex ratio 58).

We must first consider to what extent the association between the sex ratio and the weight of stillbirths is determined by the relation between the sex ratio and the weight of total births. Table I shows that the sex ratio of total births (Birmingham) decreases up to $5 \mathrm{lb}$., and then increases regularly in each weight group. There is

TABLE II

Sex Ratio of Births Subsequent to 20 WeEks of Gestation Related to Birth Weight (NEW YORK CITY 1939-1940)

\begin{tabular}{|c|c|c|c|c|c|c|}
\hline \multirow{3}{*}{$\begin{array}{c}\text { Birth Weight } \\
\text { (g.) }\end{array}$} & \multicolumn{3}{|c|}{ Stillbirths } & \multicolumn{3}{|c|}{ Total Births } \\
\hline & \multicolumn{2}{|c|}{ Percentage Distribution } & \multirow{2}{*}{ Sex Ratio } & \multicolumn{2}{|c|}{ Percentage Distribution } & \multirow{2}{*}{ Sex Ratio } \\
\hline & Males & Females & & Males & Females & \\
\hline Under 1,000 & $\begin{array}{c}28 \cdot 8 \\
(1,104)\end{array}$ & $\begin{array}{l}25 \cdot 4 \\
(799)\end{array}$ & $58 \cdot 0$ & $\begin{array}{c}1 \cdot 5 \\
(1,662)\end{array}$ & $\begin{array}{c}1 \cdot 2 \\
(1,289)\end{array}$ & $56 \cdot 3$ \\
\hline 1,000 & $\begin{array}{r}9 \cdot 9 \\
(381)\end{array}$ & $\begin{array}{l}12 \cdot 0 \\
(378)\end{array}$ & $50 \cdot 2$ & $\begin{array}{c}1 \cdot 0 \\
(1,071)\end{array}$ & $\begin{array}{c}1 \cdot 0 \\
(1,079)\end{array}$ & $49 \cdot 8$ \\
\hline 1,500 & $\begin{array}{r}9 \cdot 0 \\
(344)\end{array}$ & $\begin{array}{r}9 \cdot 7 \\
(306)\end{array}$ & $52 \cdot 9$ & $\begin{array}{c}1 \cdot 6 \\
(1,741)\end{array}$ & $\begin{array}{c}1 \cdot 8 \\
(1,903)\end{array}$ & $47 \cdot 8$ \\
\hline 2,000 & $\begin{array}{r}9 \cdot 5 \\
(366)\end{array}$ & $\begin{array}{r}9 \cdot 7 \\
(305)\end{array}$ & $54 \cdot 5$ & $\begin{array}{c}4 \cdot 7 \\
(5,203)\end{array}$ & $\begin{array}{c}5 \cdot 8 \\
(6,072)\end{array}$ & $46 \cdot 1$ \\
\hline 2,500 & $\begin{array}{r}9 \cdot 5 \\
(364)\end{array}$ & $\begin{array}{l}10 \cdot 1 \\
(316)\end{array}$ & $53 \cdot 5$ & $\begin{array}{c}16 \cdot 1 \\
(17,909)\end{array}$ & $\begin{array}{c}21 \cdot 9 \\
(22,916)\end{array}$ & $43 \cdot 9$ \\
\hline 3,000 & $\begin{array}{l}12 \cdot 9 \\
(496)\end{array}$ & $\begin{array}{l}15 \cdot 7 \\
(493)\end{array}$ & $50 \cdot 2$ & $\begin{array}{c}36 \cdot 9 \\
(41,199)\end{array}$ & $\begin{array}{c}40 \cdot 0 \\
(41,770)\end{array}$ & $49 \cdot 7$ \\
\hline 3,500 & $\begin{array}{l}10 \cdot 8 \\
(415)\end{array}$ & $\begin{array}{r}9 \cdot 9 \\
(311)\end{array}$ & $57 \cdot 2$ & $\begin{array}{c}27 \cdot 5 \\
(30,687)\end{array}$ & $\begin{array}{c}21 \cdot 9 \\
(22,864)\end{array}$ & $57 \cdot 3$ \\
\hline 4,000 & $\begin{array}{r}5 \cdot 3 \\
(202)\end{array}$ & $\begin{array}{r}4 \cdot 7 \\
(149)\end{array}$ & $57 \cdot 5$ & $\begin{array}{c}8 \cdot 8 \\
(9,811)\end{array}$ & $\begin{array}{c}5 \cdot 4 \\
(5,618)\end{array}$ & $63 \cdot 6$ \\
\hline 4,500 & $\begin{array}{c}2 \cdot 8 \\
(109)\end{array}$ & $\begin{array}{c}1.9 \\
(59)\end{array}$ & $64 \cdot 9$ & $\begin{array}{c}1 \cdot 7 \\
(1,926)\end{array}$ & $\begin{array}{r}0 \cdot 8 \\
(871)\end{array}$ & $68 \cdot 9$ \\
\hline $\begin{array}{l}5,000 \text { and } \\
\text { over }\end{array}$ & $\begin{array}{l}1 \cdot 5 \\
(57)\end{array}$ & $\begin{array}{l}0 \cdot 8 \\
(24)\end{array}$ & $70 \cdot 4$ & $\begin{array}{r}0 \cdot 3 \\
(309)\end{array}$ & $\begin{array}{r}0 \cdot 1 \\
(133)\end{array}$ & $69 \cdot 9$ \\
\hline Total & $\begin{array}{c}100 \\
(3,838)\end{array}$ & $\begin{array}{c}100 \\
(3,140)\end{array}$ & $55 \cdot 0$ & $\begin{array}{c}100 \\
(111,518)\end{array}$ & $\begin{array}{c}100 \\
(104,515)\end{array}$ & $51 \cdot 6$ \\
\hline
\end{tabular}




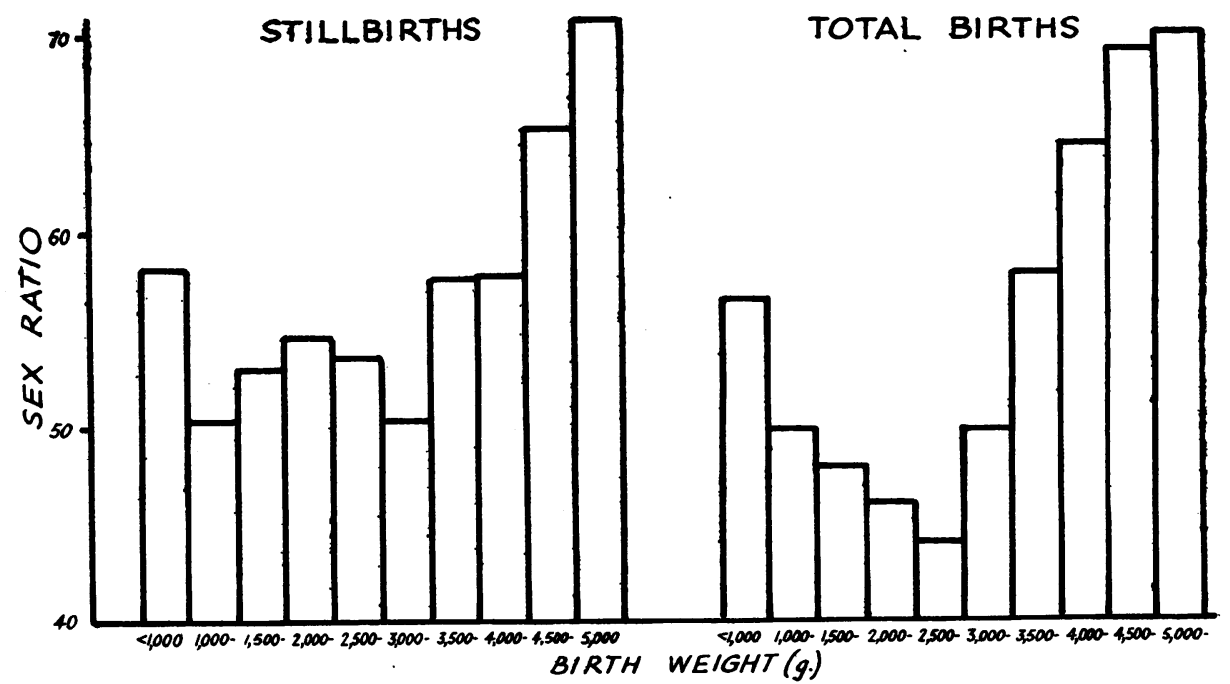

FIGURE.-Sex Ratio of Births related to Weight, New York City, 1939-40

an excess of males at the lowest weights, and a marked excess at the highest weights, but in three weight groups $(4,5$, and $6 \mathrm{lb}$.) there are more females than males. New York data exhibited in Table II (see also Figure) are entirely consistent with these observations, although no strict comparison can be made because of the different weight systems in which the observations are recorded. It is evident that the association between the sex ratio and the weight of stillbirths in part reflects the weight and sex composition of the population of total births from which they are drawn.

The second question to be considered is the relation between sex-specific stillbirth rates and birth weight, for any difference between sex ratios of total births and stillbirths in each weight group reflects the differential mortality of males and females. For this purpose we require weight distributions of the related populations of total births, and, as indicated above, this is available in Birmingham for 1947 only. Tables III and IV show what is well known, namely that stillbirth rates are high at low weights and decrease rapidly as weight increases. The Birmingham stillbirth rates (all weights) are considerably lower than those for New York because the latter include deaths between 20 and 28 weeks, and are based on statistics of 10 years earlier. Table IV shows a sharp rise in stillbirth rates at the highest weights, but in Table III numbers are too small to permit subdivision of births " $9 \mathrm{lb}$. and over". The Birmingham rates are based on only 518 stillbirths, and when male and female stillbirth rates are compared at each weight group the results are somewhat irregular (Table III). Even so, in five of the eight weight groups considered, there are no significant differences between the sex-specific stillbirth rates, and it is only at the very low weights that differences are substantial. The New York data exhibited in Table IV are based on much larger numbers, and the 
SEX RATIO OF STILLBIRTHS IN RELATION TO BIRTH WEIGHT 233

TABLE III

Sex Specific Stillbirth Rates related to Weight (Birmingham, 1947)

\begin{tabular}{|c|c|c|c|}
\hline \multirow{2}{*}{ Birth Weight (lb.) } & \multicolumn{2}{|c|}{ Stillbirth Rate } & \multirow{2}{*}{$\begin{array}{c}\text { Difference } \\
(a-b)\end{array}$} \\
\hline & (a) Male & (b) Female & \\
\hline $\begin{array}{c}\text { Under } 3 \\
3- \\
4- \\
5- \\
6- \\
7- \\
8- \\
9 \text { and over }\end{array}$ & $\begin{array}{c}326 \\
402 \\
144 \\
53 \\
16 \cdot 2 \\
15 \\
12 \\
17\end{array}$ & $\begin{array}{c}500 \\
232 \\
147 \\
40 \\
15 \cdot 6 \\
11 \\
6 \\
10\end{array}$ & $\begin{array}{c}-174 \pm 77 \\
+170 \pm 72 \\
-3 \pm 34 \\
+13 \pm 11 \\
+0 \cdot 6 \pm 3 \cdot 5 \\
+4 \pm 3 \\
+6 \pm 3 \\
+7 \pm 6\end{array}$ \\
\hline Total & $24 \cdot 4$ & $21 \cdot 0$ & $+3 \cdot 4 \pm 2 \cdot 0$ \\
\hline
\end{tabular}

TABLE IV

Sex Specific Stillbirth Rates related to Weight (New York City, 1939-1940)

\begin{tabular}{c|c|cc}
\hline \multirow{2}{*}{ Birth Weight (g.) } & \multicolumn{2}{|c}{ Stillbirth Rate } & \multicolumn{1}{c}{$\begin{array}{c}\text { Difference } \\
(a-b)\end{array}$} \\
\cline { 2 - 3 } & $(a)$ Male & $(b)$ Female & $+44 \pm 18$ \\
Under 1,000 & 664 & 620 & $+6 \pm 21$ \\
$1,000-$ & 356 & 350 & $+37 \pm 13$ \\
$1,500-$ & 198 & 161 & $+20 \pm 5$ \\
2,000 & 70 & 50 & $+6 \pm 1$ \\
$2,500-$ & 20 & 14 & $+0 \cdot 2 \pm 0 \cdot 8$ \\
3,000 & 12 & $11 \cdot 8$ & $-0 \cdot 1 \pm 1$ \\
$3,500-$ & $13 \cdot 5$ & 27 & $-6 \pm 2$ \\
$4,000-$ & 57 & 68 & $-11 \pm 10$ \\
$4,500-$ & 184 & 180 & $+4 \pm 40$ \\
5,000 and over & $34 \cdot 4$ & $30 \cdot 0$ & $+4 \cdot 4 \pm 0 \cdot 8$ \\
\hline Total &.. & & \\
\hline
\end{tabular}

TABLE $\mathrm{V}$

Sex Specific Stillbirth Rates: New York Data Grouped

\begin{tabular}{|c|c|c|c|c|c|c|c|c|c|}
\hline \multirow{2}{*}{$\begin{array}{l}\text { Birth Weight } \\
\text { (g.) }\end{array}$} & \multicolumn{3}{|c|}{ Total Births } & \multicolumn{3}{|c|}{ Stillbirths } & \multicolumn{2}{|c|}{ Stillbirth Rates } & \multirow{2}{*}{$\begin{array}{l}\text { Difference } \\
(a)-(b)\end{array}$} \\
\hline & Males & Females & $\begin{array}{c}\text { Sex } \\
\text { Ratio }\end{array}$ & Males & Females & $\begin{array}{c}\text { Sex } \\
\text { Ratio }\end{array}$ & $\begin{array}{c}(a) \\
\text { Males }\end{array}$ & $\begin{array}{c}(b) \\
\text { Females }\end{array}$ & \\
\hline \multirow{2}{*}{$\begin{array}{l}\text { Under } 3,500 \\
3,500 \text { and } \\
\text { over }\end{array}$} & 68,785 & 75,029 & $47 \cdot 8$ & 3,055 & 2,597 & $54 \cdot 1$ & $44 \cdot 4$ & $34 \cdot 6$ & $+9 \cdot 8 \pm 1 \cdot 0$ \\
\hline & 42,733 & 29,486 & $59 \cdot 2$ & 783 & 543 & $59 \cdot 0$ & $18 \cdot 3$ & $18 \cdot 4$ & $-0 \cdot 1 \pm 1 \cdot 0$ \\
\hline Total & 111,518 & 104,515 & $51 \cdot 6$ & 3,838 & 3,140 & $55 \cdot 0$ & $34 \cdot 4$ & $30 \cdot 0$ & $+4 \cdot 4 \pm 0 \cdot 8$ \\
\hline
\end{tabular}

association between sex-specific stillbirth rates and weight is more consistent. In each weight group below 3,500 g., male rates are higher than female rates; at each weight group above $3,500 \mathrm{~g}$., female rates are higher than male rates (the highest group, which is based on small numbers, excepted). 
It is evident that the difference between the sex-specific stillbirth rates (all weights) reflects:

(a) differences in rates at each weight group (as given in Tables III and IV)

(b) the different weight distribution of male and female total births at risk (as given in Tables I and II).

We can readily assess the effect of $(b)$ by standardizing for weight; this we have done for the New York data by applying the observed female sex-specific stillbirth rates in each weight group to the number of male total births in the same weight group. By this procedure, the female stillbirth rate (all weights) is increased from 30.0 to $31 \cdot 8$; that is to say the difference between the sex-specific stillbirth rates is reduced by about two-fifths.

The remainder of the difference in the sex-specific stillbirth rates is accounted for by the higher male rates at the lower weights. The New York data are grouped in Table V, which shows that for births " under 3,500 g." the male stillbirth rate is much higher than the female rate; at " $3,500 \mathrm{~g}$. and over" there is no appreciable difference between the sex-specific stillbirth rates.

Table $\mathrm{V}$ also gives sex ratios for total births and stillbirths, and enables us to understand the high sex ratio of stillbirths in both weight groups. Although there are more females than males at risk under $3,500 \mathrm{~g}$. (sex ratio $47 \cdot 8$ ), the sex ratio of stillbirths is raised $(54 \cdot 1)$ because the male stillbirth rate is much higher than the female rate. At " $3,500 \mathrm{~g}$. and over" there is no difference in the rates, but the considerable excess of males at risk (sex ratio $59 \cdot 2$ ) again results in a high stillbirth sex ratio $(59 \cdot 0)$.

It is well known that the sex ratio of stillbirths attributed to difficult labour is high. The New York data do not give cause of stillbirth, but in Birmingham (1945-49) there were 744 stillbirths due to difficult labour, for which the sex ratio was $60 \cdot 6$. It has been suggested that this high ratio may be explained by the fact that male births are on the average heavier than female births (Prinzing, 1907; Pinard and Magnan, 1913; Greulich, 1931). This view is consistent with the evidence here examined, since there are no significant differences between the sexspecific stillbirth rates at the higher weight groups in which difficult labour is the most common cause of death. (Of Birmingham stillbirths at $7 \mathrm{lb}$. and over, 55 per cent. were attributed to difficult labour.)

\section{SUMMARY}

(1) The relation between the sex ratio of stillbirths and birth weight is explored using the following data:

(i) for Birmingham, stillbirths notified in the years 1945-49

(ii) for New York City, foetal deaths during the two years 1939-40.

(2) The sex ratio of stillbirths is high because:

(a) there are more male foetuses at risk (the sex ratio of total births is about 51.5)

(b) stillbirth rates are higher for male than for female births. 
(3) The sex-specific stillbirth rates are examined in relation to weight at birth. It is shown that male rates are higher than female rates at lower weights (under $3,500 \mathrm{~g}$.), but that for births at higher weights there is no significant difference.

(4) The difference in sex-specific stillbirth rates (all weights) is due:

(a) partly to the higher male stillbirth rates at the lower weights

(b) partly to sex differences in weight distributions of related total births.

\section{REFERENCES}

Baumgartner, L., Pessin, V., Wegman, M. E., and Parker, S. L. (1950). Pediatrics, Springfield, 6, 329. Greulich, W. W. (1931). Science, 74, 53.

McKeown, T., and Lowe, C. R. (1951). Hum. Biol., 23, 41.

Pinard, A., and Magnan, A. (1913). C.R. Acad. Sci.. Paris, 156, 401.

Prinzing, F. (1907). Allg. statist. Arch., 7, 21. 